\title{
Disasters, Death, and Destruction Making Sense of Recent Calamities
}

\author{
BY ROGER A. PIELKE, JR.
}

Remarks from the Seventh Annual Roger Revelle Commemorative Lecture. This lecture was created by the Ocean Studies Board of the National Academies in honor of Dr. Roger Revelle to highlight the important links between ocean sciences and public policy. This year the lecturer was Roger A. Pielke, Jr. and the lecture was held on March 15, 2006 at the Baird Auditorium in the Smithsonian National Museum of Natural History in Washington, D.C.

\section{INTRODUCTION}

A disaster happens when an extreme event occurs in the context of societal vulnerability. Nowhere is the meeting of vulnerability and extreme more tangible than where the land meets the sea. This was horrifically apparent on 26 December 2004 when a powerful earthquake under the eastern Indian Ocean caused a massive tsunami that killed more than 280,000 people and caused billions of dollars (all dollars in this article refer to U.S. dollars) in damage. Other disasters at the ocean-land boundary are similarly fresh in our minds- the U.S. hurricane seasons of 2004 and 2005 resulted in hundreds of billions of dollars

Roger A. Pielke, Jr. (pielke@colorado. edu) is Professor, Environmental Studies Program, University of Colorado, Boulder, CO, USA, and Fellow, Cooperative Institute for Research in the Environmental Sciences (CIRES), Boulder, CO, USA. in damage and more deaths than in the previous 35 years combined. We do not have to look too far back in time to recall other tragedies, such as Hurricane Jeanne, which killed several thousand people in Haiti in 2004; the Venezuelan coastal landslides in 1999, which killed upwards of 30,000 people; and Hurricane Mitch in 1998, which killed more than 10,000 people, mainly in Nicaragua and Honduras (Taft, 2004; Pielke et al., 2003). In 1991, perhaps 150,000 people died in Bangladesh as the result of storm surge and flooding from a tropical cyclone (Pielke and Pielke, 1997).

The recent spate of disasters has created two common perceptions among decision-makers and the general public. First, there is a sense that the economic impacts associated with extreme events have increased in recent years. Second, given that a human influence on the climate system has been well established, a perception exists that the recent increase in weather-related disasters like floods and hurricanes is in some way related to changes in climate.

These perceptions beg two questions:

- Have loss of life and damages associated with extreme weather events actually increased in recent years?

- What factors account for observed trends in the impacts of weather on society?

The answers to these questions are more than simply idle speculations-they help shape how we think about policy options with important social, economic, and political ramifications (such as disaster preparation, insurance, international climate-change negotiations) and how we set priorities for the funding of scientific research. Because policy is based in part on the perceptions that policy-makers hold about weather and climate, it is worth determining the answers to the two questions in a scientifically rigorous manner. This lecture discusses trends 
in damages associated with disasters with a focus on extreme weather events, floods, and hurricanes. It also discusses factors that account for the observed trends and the state of our knowledge in this area. It concludes with a discussion of implications for policy and research related to natural hazards and global climate change.

\section{CONTEXT: DISASTERS AND GLOBAL WARMING}

Today one cannot engage in a discussion of the global trend in disasters without also discussing global warming. The increasing threat of natural disasters has long been cited as one of many reasons why society should reduce greenhouse gas emissions, and the disasters of 2004 and 2005 have only made those calls louder. For example, a day after the Indian Ocean tsunami, Sir David King, Britain's chief science adviser, said in a BBC (British Broadcasting Company) interview, "What is happening in the Indian Ocean underlines the importance of the Earth's system to our ability to live safely. And what we are talking about in terms of climate change is something that is really driven by our own use of fossil fuels" (The Guardian, 2004). Disasters are a powerful symbol in the highly politicized climate debate; consequently, the climate debate shapes how we think about disasters and what policies make sense in response.

Linkages between climate change and disasters have a rich pedigree. Environmental groups use the threat of increasing disasters to advocate decisive action to reduce the emission of greenhouse gases and to implement the Kyoto Protocol on climate change. The advo- cacy group Scientists and Engineers for Change supported John Kerry in the 2004 U.S. Presidential election by posting billboards in storm-ravaged Florida with the message, "Global Warming = Worse Hurricanes. George Bush just doesn't get it" (Figure 1). But as logical and enticing as it may seem to connect the ever-growing toll of disasters with global warming, the current state of science simply does not support making such a connection.

While politicians and political advocates might sometimes be expected to stretch the bounds of scientific accuracy, it is particularly troubling to see leading scientists join them. For instance, the former head of the United Nation's Intergovernmental Panel on Climate Change (IPCC), Sir John Houghton, testified before the U.S. Senate last July that increasing disaster losses could be attributed to increased storminess (Houghton, 2005). And Rajendra Pachuri, the current head of the IPCC, suggested in February 2004 that the escalating costs of disasters could be attributed in part to climate change (Pachuri, 2005). Yet such claims are simply not supported by existing scientific research, and thus have the potential to mislead both thinking and advocacy on policy options related to climate.

It is crucial to observe that humancaused global climate change is, of course, underway and well-documented by the scientific community. Further, developing alternative energy sources and reducing global carbon-dioxide emissions are essential. But the claim that action to slow climate change is justified by the rising toll of natural disastersand, by extension, that reducing emissions can help to significantly address these rising losses_-is both scientifically and morally insupportable. To address ever-escalating damage from hurricanes, floods, and other extreme events, we need to expand our focus on climate policy beyond simply reducing emissions to reducing our vulnerability to disasters. Reducing vulnerability requires an understanding of why it is that disasters have been increasing.

\section{UNDERSTANDING \\ DISASTER TRENDS}

The first thing to understand about disasters is that they have indeed been rapidly increasing worldwide over the past century, in both number and severity, and that the causes of this increase

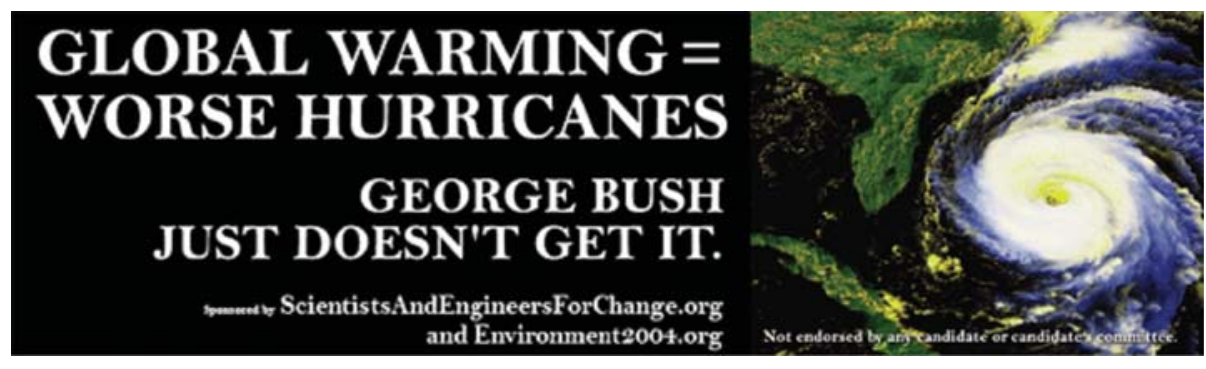

Figure 1. Billboard put up along highways in Florida during the 2004 presidential election by the groups Environment 2004, and Scientists and Engineers for Change. Photo from Environment 2004. Available online at: http://www.environment2004.org/global_warming.php. 
are well understood. Data from the Center for Research on the Epidemiology of Disasters in Brussels, Belgium, as well as the Red Cross and the reinsurance industry, show that the number of disasters affecting at least 100 people or resulting in a call for international assistance has increased from an average of about 100 per year in the late $1960 \mathrm{~s}$ to between 500 and 800 per year by the early twenty-first century (International Federation of the Red Cross and Red Crescent Societies, 2005; data from Center for Research on the Epidemiology of Disasters available at: http://www. em-dat.net/). The reason the number of people affected and number of calls for international assistance have increased is not due to the frequency or severity of storms, earthquakes, or similar events, but to a dramatic increase in vulnerability because of growing populations, expanding economies, rapid urbanization, and migrations to coasts and other exposed regions.

These changes are reflected in the costs of major disasters, which, according to the German reinsurance company $\mathrm{Mu}$ nich Re Group, rose more than tenfold in the second half of the twentieth century, from an average of about $\$ 4$ billion per year in the 1950 s to more than $\$ 40$ billion per year in the 1990s, in inflation-adjusted dollars (Munich Re Group, 2000). The great Miami hurricane of 1926, for example, caused about $\$ 76$ million in damage; when Hurricane Andrew, a smaller storm of similar intensity, struck South Florida in 1992, it caused more than $\$ 30$ billion in damage, again adjusted for inflation (Pielke and Pielke, 1997). Our research suggests that, if the same 1926 storm were to have hit Miami in 2005, it would cost more than $\$ 137$ billion (unpublished analysis by author, updated from Pielke and Landsea, 1998).

Disasters and their costs are increasing. And with them an ever-escalating economic toll on society is coming. Figure 2 shows the dramatically rising costs of disasters in recent years.

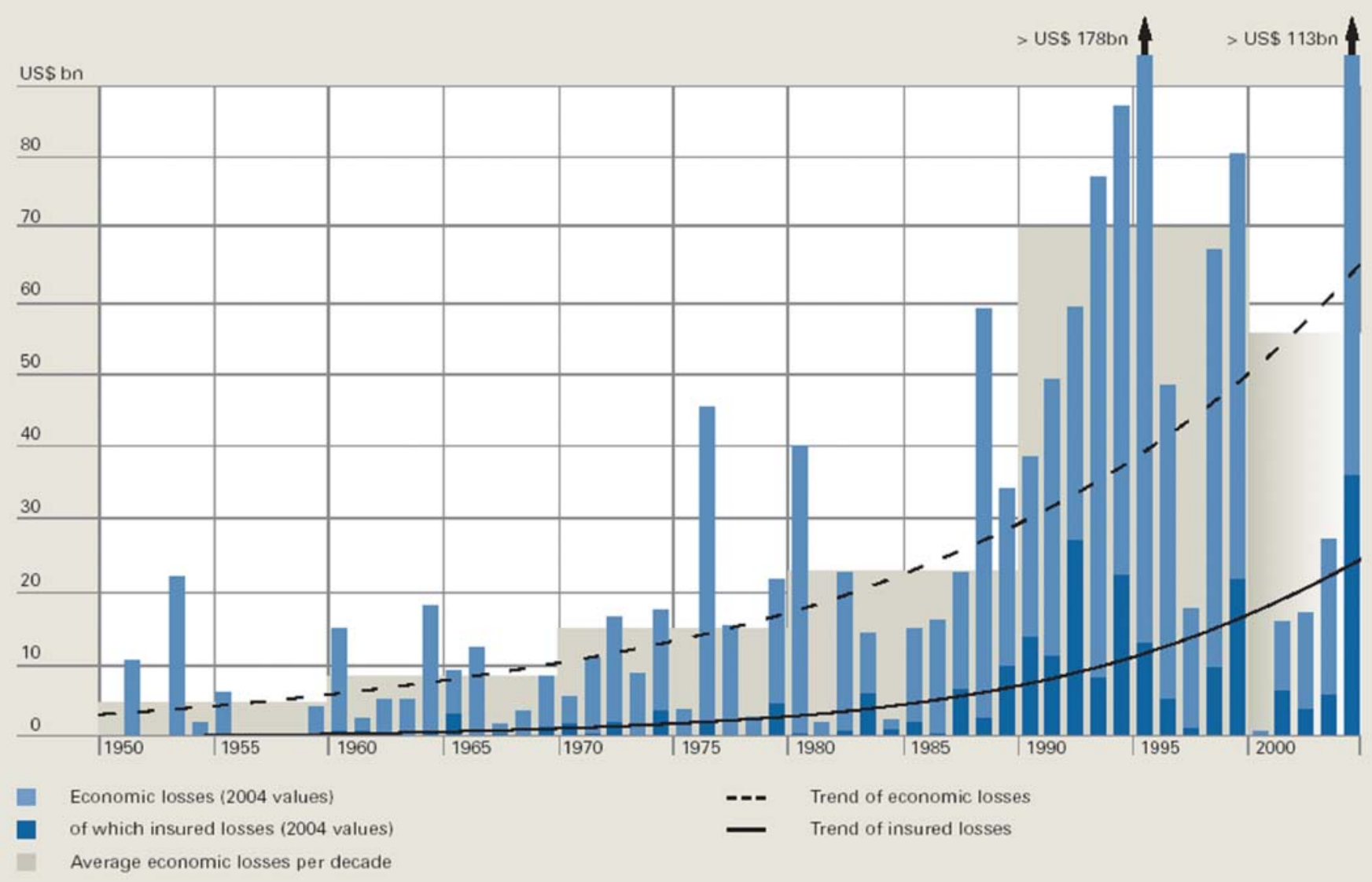

Figure 2. The growing global toll of disasters, according to data collected by Munich Re Group. Source: Munich Re Group (2005). 
The economic losses from disasters are increasingly concentrated in the affluent world. But, as a percentage of GNP, the economic effects of natural disasters on poor countries can be hundreds of times greater. For example, Hurricane Mitch, which devastated Central America in 1998, caused damages estimated as much as $\$ 8.5$ billion or about the annual combined total economic activity of the two hardest-hit nations, Honduras and Nicaragua (Pielke et al., 2003). Their economies still have not recovered. By comparison, the magnitude 6.7 earthquake that struck California in 1994, one of the costliest disasters in U.S. history, caused an estimated $\$ 20$ to $\$ 40$ billion in losses, but this amounted to only 2 to 4 percent of California's economic activity (Sarewitz and Pielke, 2005).

Disasters disproportionately harm poor people in poor countries because those countries typically have densely populated coastal regions, shoddily constructed buildings, sparse infrastructure, and grossly inadequate public health capabilities. Poor land use leads to widespread environmental degradation, such as deforestation and wetlands destruction, which in turn exacerbates flooding and landslides. Emergency preparation and response capabilities are often inadequate and hazard insurance is usually unavailable, further slowing recovery. Thus, while the world's poorest 35 countries make up only about 10 percent of the world's population, they suffered more than half of the disaster-related deaths between 1992 and 2001 (Jones, 1997).

Disparities in disaster vulnerability between rich and poor will continue to grow. About 97 percent of population growth is occurring in the developing world. This growth, in turn, drives urbanization and coastal migration. The result is that the population of urban areas in the developing world will likely spells," or in "tornados, hail, and other severe weather." In the absence of trends in these weather events, they cannot be identified as being responsible for

\section{But as logical and enticing as it may seem to connect the ever-growing toll of disasters with global warming, the current state of science simply does not support making such a connection.}

increase by two billion people in the next two decades. And this population is being added to cities that are mostly located on coastal or flood plains - or in earthquake zones_-and are unable to provide the quality of housing, services, infrastructure, and environmental protection that can help reduce vulnerability. Uncontrolled urban growth exacerbates exposure to extreme events.

\section{SOME DETAILS AND DATA}

If we hypothesize that changes in weather patterns are responsible for some part of the trend of increasing disaster losses, then it is logical that the first place we might look for changes is in the behavior of weather extremes. The most recent IPCC report took a close look at research on extreme weather events and found little evidence for changes over time (IPCC, 2001a).

Consider that over recent decades, the IPCC found no long-term global trends in extra-tropical cyclones (i.e., winter storms), in "droughts or wet any part of the growing economic toll. More recently, Massachusetts Institute of Technology's Kerry Emanuel published a study in the journal Nature that described an increase in the intensity of hurricanes in the North Atlantic and North Pacific, but this trend is not related to increasing damage (Emanuel, 2005). Emanuel writes on his web site (http://wind.mit.edu/\%7Eemanuel/anthro2.htm), "There is a huge upward trend in hurricane damage in the U.S., but all or almost all of this is due to increasing coastal population and building in hurricane-prone areas. When this increase in population and wealth is accounted for, there is no discernible trend left in the hurricane damage data." Indeed, a comment I wrote in response to Emanuel's paper (2005), also published in Nature, provided evidence that indicated that once U.S. hurricane damage was adjusted to reflect societal changes, there was no trend of increasing damages over the twentieth century or an increase in damages per storm 
(Pielke, 2005). Another prominent study has found an increase in the proportion of the strongest storms (Webster et al., 2005), and scientists have differing expectations about the cause of this trend, but no one has connected such trends to increasing disasters.

The IPCC did find "a widespread increase in heavy and extreme precipitation events in regions where total precip- itation has increased, e.g., the mid- and high latitudes of the Northern Hemisphere" (IPCC, 2001a). But, at the same time, the IPCC warned that "an increase (or decrease) in heavy precipitation events may not necessarily translate into annual peak (or low) river levels" (IPCC, 2001a). Indeed, while the IPCC found some changes in streamflow, it did not identify changes in streamflow extremes

(a) U.S. Total Flood Damage, 1934-2000

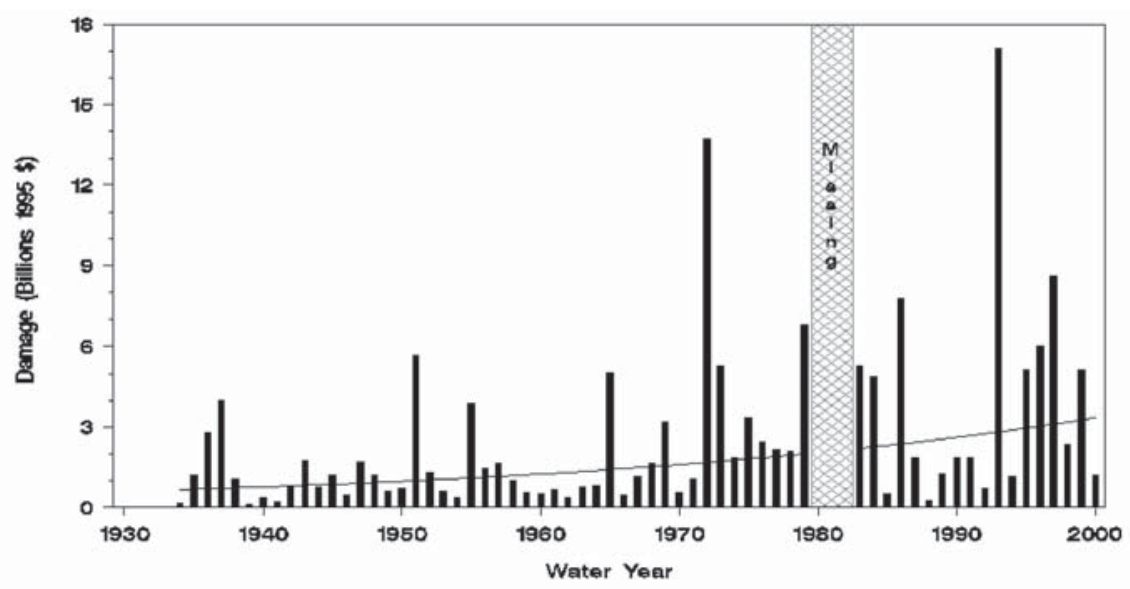

(b) U.S. Flood Damage per Unit Wealth, 1934-1998

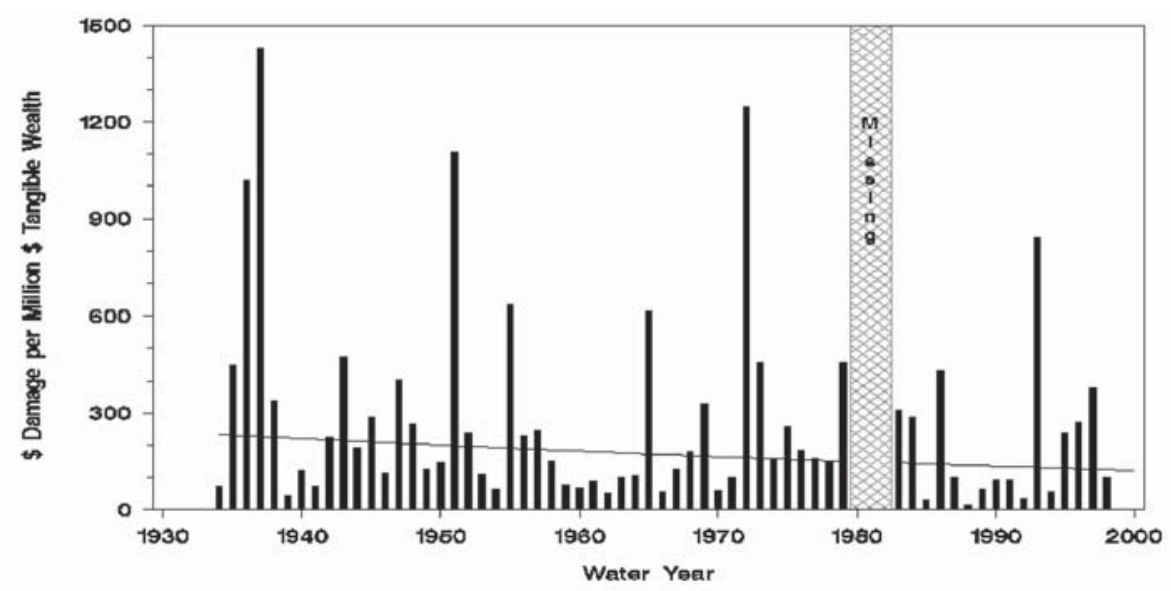

Figure 3. (a) Trends in U.S. flood damage, 1934-2000, adjusted for inflation. Source: Reprinted from Downton et al., 2005; data from http://www.flooddamagedata.org. (b) Trends in U.S. flood damage per unit of wealth, 1934-1998. Reprinted from Downton et al., 2005; data from http://www.flooddamagedata.org.

(i.e., floods), and concluded on a regional basis that, "Even if a trend is identified, it may be difficult to attribute it to global warming because of other changes that are continuing in a catchment.” A recent study by the International Ad Hoc Detection and Attribution Group (2005), published in the Journal of Climate, was unable to detect a greenhouse gas signal in global precipitation.

These findings are consistent with research seeking to document a climate signal in a long-term record of flood damage, which has concluded that an increase in precipitation does indeed contribute to increasing flood damage, but the precise amount of this increase is small and difficult to identify in the context of the much larger effects of policy and the ever-growing societal vulnerability to flood damage. Figure 3a shows how flood damage has increased dramatically in the United States, but Figure 3b shows that it has stayed almost constant when growing national wealth is considered.

The case of hurricane impacts in the United States is similarly instructive. Consider economic damage (adjusted for inflation) related to hurricane landfalls in the United States, 1900-2005, as shown in Figure 4. Although damage is growing in both frequency and intensity, this trend does not reflect increased frequency or strength of hurricanes. In fact, while hurricane frequencies have varied a great deal over the past $100+$ years, they have not increased in recent decades in parallel with increasing damages. To the contrary, although damage increased during the 1970s and 1980s, hurricane activity was considerably lower than in previous decades.

To explain the increase in damage, it 
Total Losses per Year from Atlantic Tropical Cyclones in 2005 Dollars

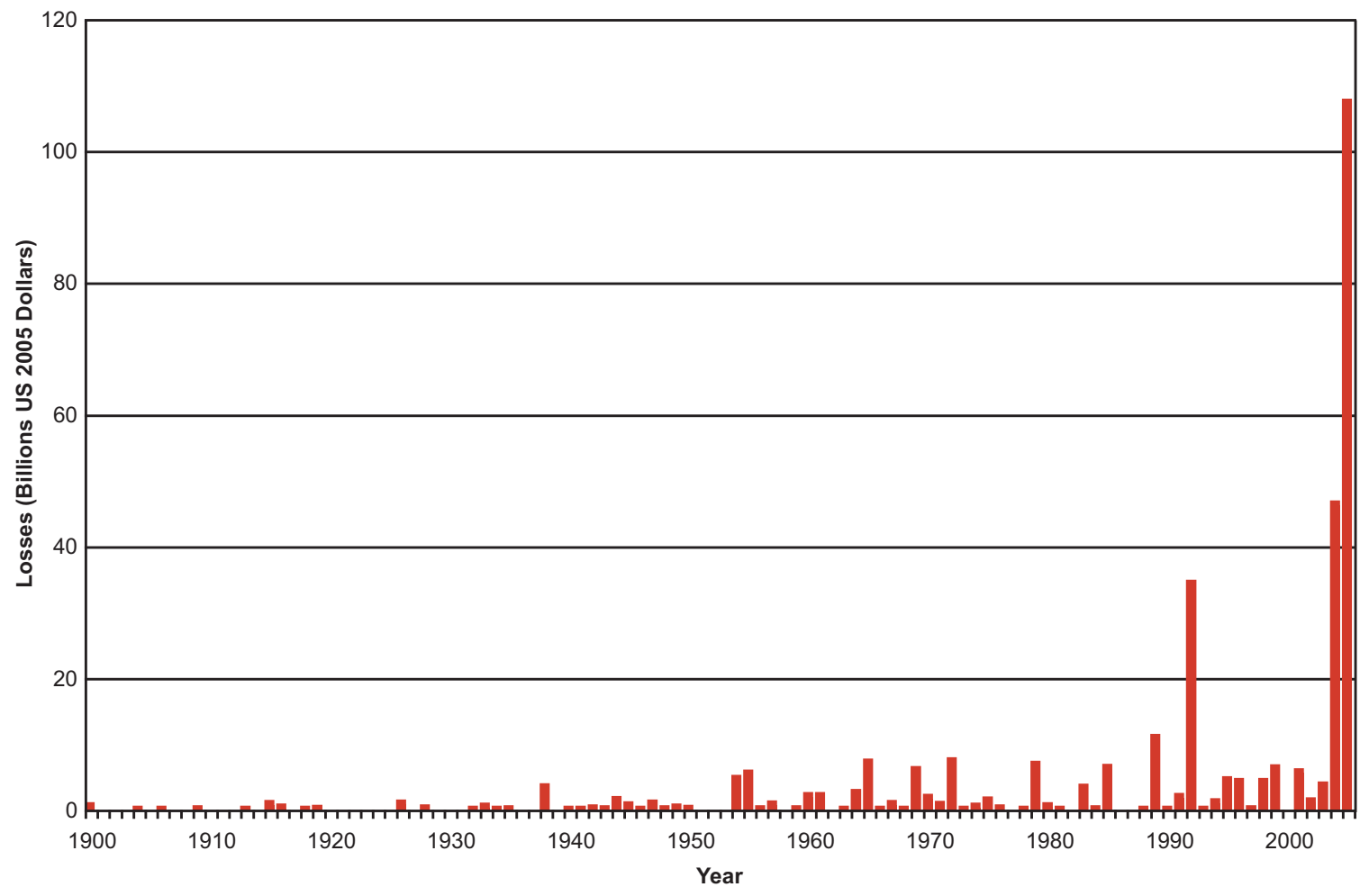

Figure 4. Trend in U.S. hurricane damage, 1900-2005. Source: NOAA/NHC (http://www.nhc.noaa.gov/gifs/table13a.gif).

is therefore necessary to consider factors other than variability or change in climate. Society has changed enormously during the past century and coastal development has taken pace at an incredible pace.

Given the significance of societal change in trends of hurricane damage, one way to present a more accurate perspective on such trends is to consider how past storms would affect present society. We developed a methodology for "normalizing" past hurricane damage to present-day values (using wealth, population, and inflation). Figure 5 shows the historical losses of Figure 4 normalized to 2005 values. The normalized record shows that the impacts of Hurricane
Andrew, at close to $\$ 53$ billion (2005 values) (unpublished analysis by author, updated from Pielke and Landsea, 1998), would have been far surpassed by the Great Miami Hurricane of 1926, which would have caused an estimated $\$ 137$ billion damage had it occurred in 2005, exceeding similarly accounted costs of Katrina. We can have some confidence that the normalized loss record accounts for societal changes because, unlike the unadjusted data, the adjusted damage data accurately reflect well-understood patterns of climate variability, such as the signal of El Niño and La Niña in hurricane frequencies.

This methodology helps to illustrate the profound sensitivity of future climate impacts to societal change, in the context of climate and societal changes projected by the IPCC (IPCC, 2001a). While IPCC data and predictions indicate that human-caused climate change may have an effect on future disasters, our analysis of hurricanes and tropical cyclones, using IPCC data and assumptions, shows that for every $\$ 1$ of additional disaster damage scientists expect will be caused by the effects of global warming by 2050, an additional $\$ 22$ to $\$ 100$ of damages will result from the growth of economies and populations. Other studies of hurricanes, flooding, and heat waves lead to a similar conclusion: socioeconomic trends, not climate change, will continue to drive increasing disaster losses. 


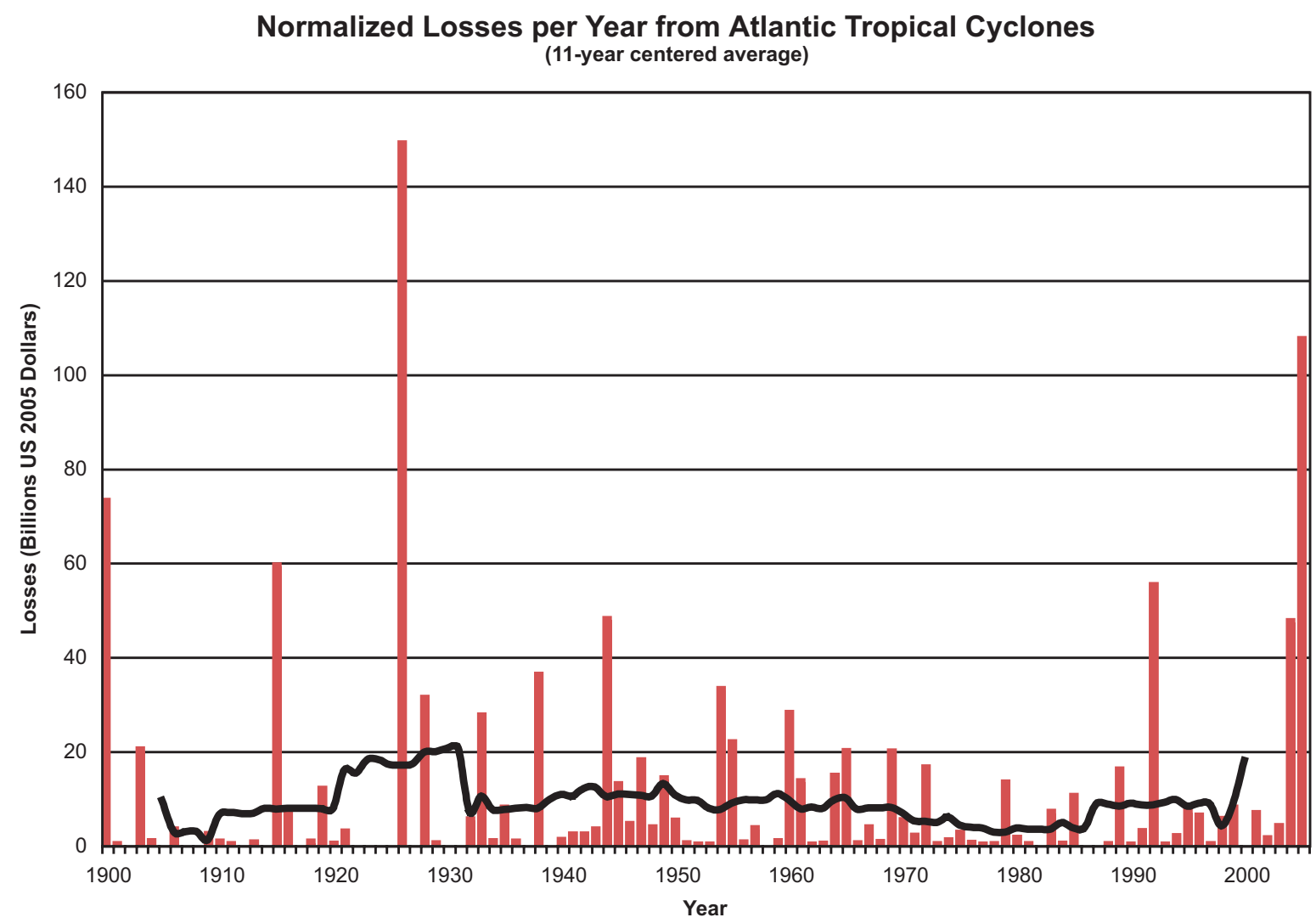

Figure 5. Estimated hurricane damages 1900-2005 if storms of the past made landfall with coastal development of 2005. The black line is the 11-year centered moving average of estimated hurricane damage. Source: Roger A. Pielke, Jr.

\section{CLARITY FROM CONFUSION}

While it is understandable why some advocacy groups might stretch the bounds of present scientific understanding to link recent disasters and climate change to advance a political agenda, scientists should know better than to make the same claims.

One important reason for some confusion among scientists stems from a claim made by the IPCC Working Group II (IPCC, 2001b) attributing some part of the trend of increasing disaster losses to changes in climate. However, upon closer look, the claim seems unfounded. The IPCC relied on a report published in 2000 by Munich Re that found that global disasters resulted in $\$ 636$ billion in losses in the 1990s compared with $\$ 315$ billion in the 1970s, after adjusting for changes in population and wealth. The Munich Re report concludes that disaster costs have increased by a factor of two (i.e., 636/315) (Munich Re Group, 2000), independent of societal changes; the IPCC suggests that climate change is responsible for the difference.

Methodologically, the calculation is suspect for a number of reasons. First, Munich Re Group provides neither their methods nor data. Second, Munich Re Group admits that data on changes in wealth are not available around the world and changes in GDP are not always a good proxy for data on wealth. Third, Munich Re Group's data apparently includes weather and non-weather events (e.g., it appears to also include earthquake damages).

But let's assume that all of the issues raised above can be overcome, and in the end there remains a 2 -to- 1 ratio. The fact is that the large decadal variability in disaster losses makes it quite dodgy to assert a trend by comparing two different ten-year periods over a period of 30 years. This can be illustrated with an example from our database of hurricane 
losses. If we adjust the hurricane-loss data, accounting for trends in population, wealth, and inflation, to 2005 values and then compare decades (unpublished analysis by author, updated from Pielke and Landsea, 1998), we see some interesting things. Figure 5 shows these data. First, the ratio of the 1990s to the 1970s is quite similar to the Munich Re Group's analysis, 2.1 (\$87B/\$41B). But, if we look at other decadal comparisons, the picture looks quite different, the 1990s to the $1940 \mathrm{~s}=0.8(\$ 87 \mathrm{~B} / \$ 110 \mathrm{~B}) \mathrm{com}-$ pared to the $1990 \mathrm{~s}$ to the $1920 \mathrm{~s}=0.5$ $(\$ 87 \mathrm{~B} / \$ 184 \mathrm{~B})$. The bottom line is that the 2000 Munich Re Group's analysis tells us nothing about the attribution of the causes for increasing disasters, yet its results were used by the IPCC to suggest otherwise.

\section{WHERE FROM HERE?}

Despite robust scientific research to the contrary, assertions persist that global warming is directly linked to rising disaster losses. For those seeking to raise public concern, such assertions may have short-term political benefits in the global-warming debate, but they detract from serious efforts to prepare for disasters. To emphasize, humans have an effect on the global climate system and reducing greenhouse-gas emissions makes good sense. But reducing emissions will not discernibly affect the trend of escalating disaster losses because the cause of that increase lies in ever-growing societal vulnerability. Faced with the inescapable momentum of these socioeconomic trends, the crucial question is this: What can be done to better prepare the world-especially the developing world-for future disasters?
Once we understand that the chief reason for increasing disaster losses is the role of demographics in making a country vulnerable to disaster, we can better focus responses on managing vulnerability. But the narrow focus of the climate debate to date on emissions reductions has worked against a clear focus on vulnerability.

The U.N. Framework Convention, for example, has refused to fund disaster preparedness efforts unless states could demonstrate exactly how the disasters they feared were linked to climate change (more information available at http://www.unfccc.int). Consider, too, the amount spent on scientific research. According to a recent RAND study, U.S. funding for disaster loss-reduction research in 2003 amounted to about gained momentum. By contrast, the U.S. government has sponsored a coordinated, multi-agency framework for climate-change research for more than 15 years, with total investments of more than $\$ 30$ billion, adjusted for inflation (Sarewitz and Pielke, 2005).

This is not to say that many thousands of people and hundreds of organizations worldwide are not productively confronting disaster vulnerability, but their efforts do not begin to address the magnitude of the problem. Thousands of participants from most of the world's nations, along with scientists and political advocates, have come together every year since 1995 to work toward concerted international action on climate change. But, when the U.N. World Conference on Disaster Reduction met

\section{Despite robust scientific research to the contrary, assertions persist that global warming is directly linked to rising disaster losses. For those seeking to raise public concern, such assertions may have short-term political benefits in the global warming debate, but they detract from serious efforts to prepare for disasters.}

$\$ 127$ million-only 7 percent of the amount invested in climate-change research for that year (Meade and Abbott, 2003). Efforts in Congress to create a coordinated research program focused on reducing disaster losses have never in January 2005, it was the first such meeting in more than a decade (more information available at http://www. unisdr.org/wcdr).

While the prospects for global climate change are constantly in the public eye, 
For almost half a century, Roger Revelle was a leader in the field of oceanography. Revelle trained as a geologist at Pomona College and at U.C. Berkeley. Then, in 1936, he received his Ph.D. in oceanography from the Scripps Institution of Oceanography. As a young naval officer, he helped persuade the Navy to create the Office of Naval Research (ONR) to support basic research in oceanography and was the first head of ONR's geophysics branch. Revelle served for 12 years as the Director of Scripps (1950-1961, 1963-1964), where he built up a fleet of research ships and initiated a decade of expeditions to the deep Pacific that challenged existing geological theory.

Revelle's early work on the carbon cycle suggested that the sea could not absorb all the carbon dioxide released from burning fossil fuels. He calculated the first continual measurement of atmospheric carbon dioxide, leading to a long-term record that makes presentday discussions on research on global warming possible and very valuable. Revelle kept the issue of increasing carbon dioxide levels before the public and spearheaded efforts to investigate the mechanisms and consequences of climate change.

Revelle was a proponent of daring programs, like Mohole and the International Indian Ocean Expedition, which addressed fundamental scientific questions and pioneered international cooperation. In 1960, Revelle left Scripps for critical posts as Science Advisor to the Department of the Interior (1961-1963) and as the first Director

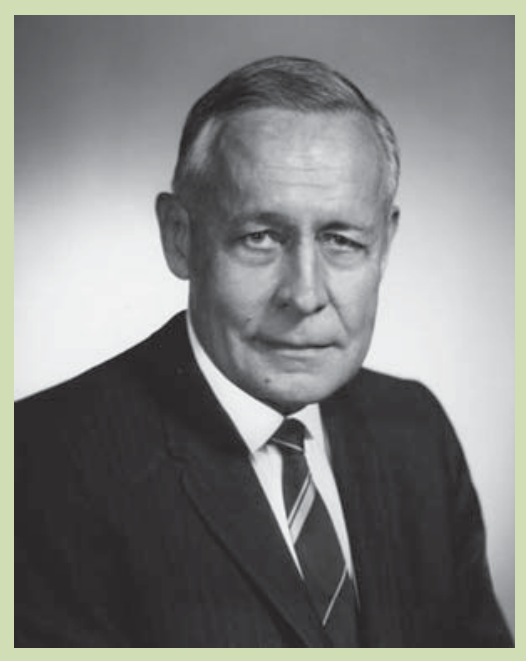

of the Center for Population Studies at Harvard (1964-1976). Revelle applied his knowledge of geophysics, ocean resources, and population dynamics to the world's most vexing problems: poverty, malnutrition, security, and education.

In 1957, Revelle became a member of the National Academy of Sciences (NAS) to which he devoted many hours of volunteer service. He served as a member of the Ocean Studies Board, the Board on Atmospheric Sciences and Climate, and many committees. He also chaired a number of influential Academy studies on subjects ranging from the environmental effects of radiation to understanding sea-level change. (Photo Credit: SIO Archives, UCSD)
Hurricane Katrina and the South Asian earthquake and tsunami poignantly demonstrate that the crisis of growing disaster vulnerability only becomes news after disaster strikes. Yet we know that effective action is possible to reduce disaster losses even in the face of poverty and dense population. During the 2004 hurricane season, Haiti and the Dominican Republic, both on the island of Hispaniola, provided a powerful lesson in this regard. As Julia Taft of the U.N. Development Program explained: "In the Dominican Republic, which has invested in hurricane shelters and emergency evacuation networks, the death toll was fewer than ten, as compared to an estimated two thousand in Haiti.... Haitians were a hundred times more likely to die in an equivalent storm than Dominicans" (Taft, 2005).

Most tools needed to reduce disaster vulnerability already exist, such as riskassessment techniques, better building codes and code enforcement, land-use standards, and emergency-preparedness plans. The question is: Why is disaster vulnerability so low on the list of global development priorities? Says Brian Tucker, president of GeoHazards International: "The most serious flaw in our current efforts is the lack of a globally accepted standard of acceptable disaster vulnerability, and an action plan to put every country on course to achieve this standard. Then we would have a means to measure progress and to make it clear which countries are doing well and which are not. We need a natural disaster equivalent to the Kyoto Protocol" (Sarewitz and Pielke, 2005).

Those who justify the need for greenhouse-gas reductions by exploiting the 
mounting human and economic toll of natural disasters worldwide are either ill-informed or disingenuous. This is not, as Britain's Sir David King suggested, "something we can manage" simply by decreasing our use of fossil fuels (The Guardian, 2004).

In principle, fruitful action on both climate change and disasters should proceed simultaneously. In practice, this will not happen until the issues of climate change and disaster vulnerability are clearly separated in the eyes of the media, the public, environmental activists, scientists, and policy-makers. There are good reasons for more substantial action on energy policies, particularly in the United States; and there are good reasons for concern about the growing toll of disaster losses around the world. But suggestions that the escalating disaster losses should motivate action on energy policy simply cannot lead to an effective approach to disaster management.

\section{ACKNOWLEDGEMENTS}

I'd like to thank the National Research Council's Ocean Studies Board for the opportunity to synthesize this work and present it as their 2006 Roger Revelle lecturer, and in particular Shirel Smith and Susan Roberts of the NRC. Nancy Caputo of the NRC expertly assisted in helping to turn the lecture into the more scholarly format you see as the end product. The material presented here draws from a wide range of publications that I have been involved in over the past decade or so, which have benefited from long-time collaboration with numerous people. In particular, I'd like to acknowledge especially my longtime collaborator Dan Sarewitz, whose many cogent ideas and words to express those ideas can be found in the synthesis above. On the updated and as-yet-unpublished normalized hurricane loss figures, I'd like to thank Joel Gratz, who I am currently working with on updating this analysis to 2005. Of course, the collaborations have added considerable value, though the responsibility for what appears in this essay lies entirely with me. If you'd like to read more or access the technical studies on this subject, the publications that I have been involved in can be found online at our web site: http://sciencepolicy.colorado.edu.

\section{REFERENCES}

Downton, M.W., J.Z. Barnard Miller, and R.A. Pielke Jr. 2005. Reanalysis of U.S. National Weather Service Flood Loss Database. Natural Hazards Review (Feb.):13-22.

Emanuel, K. 2005. Increasing destructiveness of tropical cyclones over the past 30 years. Nature 436:686-688.

Houghton, J. 2005. “Climate Change Science and Economics". Testimony to the U.S. Senate, Energy and Natural Resources Committee, Full Committee Hearing. July 21, 2005. [Online] Available at: http://energy.senate. gov/public/index.cfm?FuseAction=Hearings. Testimony\&Hearing_ID $=1484 \&$ Witness_ ID $=4228$ [last accessed May 2, 2006].

International Federation of the Red Cross and Red Crescent Societies. 2005. World Disasters Report Kumarian Press Inc., Bloomfield, CT. [Online] Available at: http://www.ifrc.org/publicat/ wdr2005/order.asp [last accessed May 2, 2006].

International Ad Hoc Detection and Attribution Group. 2005. Detecting and attributing external influences on the climate system: A review of recent advances. Journal of Climate 18(9):1,2911,314 .

IPCC. 2001a. Climate Change 2001: The Scientific Basis. Contributions of Working Group I to the Third Assessment Report of the Intergovernmental Panel on Climate Change (J.T. Houghton, Y. Ding, D.J. Griggs, M. Noguer, P.J. van der Linden, and D. Xiaosu). Cambridge University Press, United Kingdom, 881 pp.

IPCC. 2001b. Climate Change 2001: Impacts, Adaptation, and Vulnerability. Working Group II (McCarthy, J.J., O.F. Canziani, N.A. Leary, D.J. Dokken, and K.S. White). Cambridge University Press, Cambridge, United Kingdom, 1032 pp.
Jones, C.I. 1997. On the evolution of the world income distribution. Journal of Economic Perspectives 11(3):19-36.

Meade, C., and M. Abbott. 2003. Assessing Federal Research and Development for Hazard Loss Reduction. RAND Corporation, Washington, D.C. [Online] Available at: http://www.rand. org/pubs/monograph_reports/MR1734/index. html [last accessed May 2, 2006].

Munich Re Group. 2000. Topics, 2000: Natural Catastrophes, The Current Position. Münchener Rückversicherung-Gesellschaft, Munich, Germany. [Online] Available at: http://www. munichre.com/publications/302-02354 en.pdf?rdm=80335 [last accessed May 2, 2006].

Munich Re Group. 2005. Knowledge Series: Topics Geo. Annual Review: Natural Catastrophes. Münchener Rückversicherung-Gesellschaft, Munich, Germany. [Online] Available at: http://www.munichre.com/publications/30204321_en.pdf?rdm $=71234 \% 20$ [last accessed May 2, 2006].

Pachauri, R.K. 2005. "Avoiding Dangerous Climate Change-The 2nd Keynote Address." Presented at Avoiding Dangerous Climate Change, a conference sponsored by the United Kingdom Department of Environment, Food and Rural Affairs on February 1-3, 2005 in Exeter, United Kingdom. [Online] Available at: http://www. stabilisation2005.com/day1/Pachauri.pdf [last accessed May 2nd, 2006].

Pielke, Jr., R.A., 2005. Are there trends in hurricane destruction? Nature 438:E11.

Pielke, Jr., R.A., and R.A. Pielke, Sr. 1997. Hurricanes: Their Nature and Impacts on Society. John Wiley and Sons Press, London, United Kingdom.

Pielke, Jr., R.A., and C.W. Landsea. 1998. Normalized hurricane damages in the United States: 1925-95. Weather and Forecasting, American Meteorological Society 13:621-631.

Pielke, Jr., R.A., J. Rubiera, C. Landsea, M. Fernandez, and R.A. Klein. 2003. Hurricane vulnerability in Latin America and the Caribbean. Natural Hazards Review 4:101-114.

Sarewitz, D., and R.A. Pielke, Jr. 2005. "Rising Tide.” The New Republic, January 6.

Taft, J. 2004. “Storm-Tossed Lessons." The New York Times, 3 October.

The Guardian. 2004. "Tsunami highlights climate change risk, says scientist.” 31 December. Press Association. [Online] Available at: http://education.guardian.co.uk/higher/sciences/story/0,12243,1381430,00.html [last accessed May 2, 2006].

Webster, P.J., G.J. Holland, J.A. Curry, and H.R. Chang. 2005. Changes in tropical cyclone number, duration, and intensity in a warming Environment. Science 309(5742):1,844-1,846. 